\title{
Fractional Order SMC for Speed Control of PMSM
}

\author{
Fardila Mohd Zaihidee \\ Power Electronics and Renewable \\ Energy Research Laboratory, \\ Department Of Electrical Engineering \\ University of Malaya \\ Kuala Lumpur, Malaysia \\ farrmz@yahoo.com
}

\author{
Saad Mekhilef \\ Power Electronics and Renewable \\ Energy Research Laboratory, \\ Department Of Electrical Engineering \\ University of Malaya \\ Kuala Lumpur, Malaysia \\ saad@um.edu.my
}

\author{
Marizan Mubin \\ Department Of Electrical Engineering \\ University of Malaya \\ Kuala Lumpur, Malaysia \\ marizan@um.edu.my
}

\begin{abstract}
A fractional order sliding mode control with PID sliding surface design (FOSMC-PID) is proposed in this research. This controller incorporates fractional calculus which has a slower energy transfer compared to integer order calculus in order to suppress the chattering. Stability of this controller is analyzed using Lyapunov stability theorem. Simulation results proved that the proposed FOSMC speed controller performs as a robust and fast anti-disturbance controller to regulate the speed of a PMSM and proven its advantages against SMC controllers. The proposed sliding surface design also improves the FOSMC in terms of torque ripple reduction, chattering reduction and anti-disturbance properties, compared to FOSMC with PI or PD sliding surface.
\end{abstract}

Keywords - fractional order, sliding mode control, PMSM, speed control

\section{INTRODUCTION}

Permanent magnet synchronous motors (PMSM) are widely used in low to mid power application and high performance drives e.g. robotics, electric vehicles and machine tools. They are preferred over brush-type motors and gradually replacing induction motors in various fields of application due to its advantages such as compact structure, high air-gap flux density, high power density, high torque to inertia ratio, high efficiency and low maintenance properties. However, PMSM system is nonlinear and consists of timevarying parameters with high-order complex dynamics $[1,2]$.

High performance application of PMSM requires its speed controller to result in fast response, precise tracking, small overshoot and strong disturbance rejection ability. Linear control algorithms e.g. PI controller have been widely used for speed control of PMSM, but the performances were unsatisfactory in terms of tracking ability and robustness [3]. Hence, robust nonlinear control methods have been proposed and used to enhance speed control performance of PMSM. These methods include sliding mode control [1, 4-7], predictive control $[8,9]$, backstepping control [10], adaptive control $[11,12]$, automatic disturbance rejection control [13] and artificial intelligence incorporated controllers [7, 14].

Sliding mode control (SMC) is a class of variable structure systems (VSS). Its theory was originated in late 1950s in the former USSR by Prof. V. I. Utkin and Prof. S. V. Emelyanov $[15,16]$. SMC has been successfully implemented in many fields [17-21]. The key idea of SMC is to reduce the

The authors would like to acknowledge the financial support from the University of Malaya, Malaysia, through Frontier Research Grant No. FG007-17AFR and Innovative Technology Grant No. RP043B-17AET. complexity of high order systems to first order state variables namely the sliding function and its derivative [22]. It is well known as a robust control method, which can guarantee excellent tracking although the system is exposed to internal parameter variations and external disturbances. Other remarkable. features of SMC are its high accuracy and simplicity. The main disadvantage of SMC method is the chattering phenomenon originated from high frequency switching near the sliding surface by discontinuous control law in SMC design and from parasitic dynamics interactions $[1,4,23]$. Chattering can affect the system in terms of reducing control accuracy, resulting in high heat losses in electrical power circuits and high wear of moving mechanical parts [24].

In order to successfully utilize the advantages of SMC in terms of robustness and simplicity, chattering effects in SMC should be eliminated or significantly reduced to obtain excellent control accuracy. The challenge in doing so lies in how robustness and chattering effect are closely related to each other, where robustness is jeopardized in order to suppress the chattering and vice versa. Recent research on SMC are focusing on improvement to balance both properties to come out with a robust, chattering-free sliding mode controller.

This work focuses on the speed control of PMSM using a type of SMC namely a fractional order SMC, which uses fractional calculus theory in its sliding surface design. Fractional order term provides an extra degree of freedom for the SMC which improves its robustness and accuracy. On top of that, properties of fractional calculus in fractional order SMC contributes in chattering reduction.

In terms of sliding surface design, Zhang, et al. [4] has chosen a fractional integration (PI) surface whereas Huang, et al. [25] has chosen a fractional differentiation (PD) surface. From Jafarov, et al. [26], it has been proven that a PID sliding surface provides faster response than a PD sliding surface. The PID proportional term drives the system state to the switching surface neighbourhood, whereas the integral term forces the states onto the surface regardless of the bound knowledge of uncertainties and disturbances. With incorporation of the derivative term, the system will be stabilized by preventing excessive control effect of the integral action [27]. This work proposed a fractional order sliding mode control with PID sliding surface design for speed control of PMSM. 


\section{FIELD-ORIENTED CONTROL OF PMSM}

In field oriented control of PMSM, the mathematical model of the motor is defined in equation (1)-(3) $[2,4]$, where $u_{d}^{*}, u_{q}^{*}$ are the $d, q$-axis stator voltages respectively, $i_{d}^{*}, i_{q}^{*}$ are the $\mathrm{d}, \mathrm{q}$-axis stator currents respectively, $\mathrm{L}_{\mathrm{d}}, \mathrm{L}_{\mathrm{q}}$ are the $\mathrm{d}, \mathrm{q}$-axis stator inductances respectively, $T_{e}$ is the electric torque, $I_{d f}$ is the equivalent $d$-axis magnetizing current, $L_{m d}$ is the $d$-axis mutual inductance, $n_{p}$ is the pole pair, $\omega_{f}$ is the inverter frequency and $\omega_{r}$ is the rotor speed. $\lambda_{d}, \lambda_{q}$ are the $d, q$-axis stator flux linkages, which are defined in equation (4) and (5). Motor dynamics is described in equation (6), where $J$ is the moment of inertia, $B_{m}$ is the viscous friction coefficient and $T_{\mathrm{L}}$ is the load torque.

$$
\begin{gathered}
u_{d}^{*}=R_{s} \dot{d}_{d}^{*}+\dot{\lambda}_{d}-\omega_{f} \lambda_{q} \\
u_{q}^{*}=R_{s} i_{q}^{*}+\dot{\lambda}_{q}+\omega_{\mathrm{f}} \lambda_{d d} \\
T_{e}=1,5 n_{p}\left[L_{m d} I_{d j} i_{q}^{*}+\left(L_{d} L_{q}\right) i_{d}^{*} i_{q}^{*}\right] \\
\lambda_{q}=L_{q} i_{q}^{*} \\
\lambda_{d}=L_{d} \dot{d}_{d}^{*}+L_{m d} I_{d f} \\
T_{e}=J \dot{\omega}_{\mathrm{r}}+B_{m} \omega_{\mathrm{r}}+T_{L}
\end{gathered}
$$

In constant torque angle (CTA) control strategy $\left(\delta=90^{\circ}\right)$, d-axis stator current command, $i_{d}{ }^{*}$ is set to be zero. Electromagnetic torque in equation (3) can be simplified as in equation (7) and state equation of the servo drive is obtained as per equation (8).

$$
\begin{gathered}
T_{e}=1.5 n_{p}\left[L_{m \alpha} I_{d j} i_{q}^{*}\right]=k_{l} i_{q}^{*} \\
\dot{\omega}_{\mathrm{r}}=-\left(B_{w} / J\right) \omega_{\tau}+(k / J) i_{q}^{*}-T_{L} / J
\end{gathered}
$$

In this study, the main control problem is to ensure the motor speed, $\omega_{\mathrm{r}}$ to track the desired speed command, $\omega_{\mathrm{r}}^{*}$ asymptotically. For this purpose, the main speed controller i.e. the sliding mode controller provides an output in terms of qaxis stator current command, $i_{q}^{*}$ as the control input for the inner $q$-axis current controller. The speed tracking error, $e(t)$ and its derivative are defined in equation (9) and (10) respectively, where $a, b, c, \emptyset(\mathrm{t})$ and $\delta(\mathrm{t})$ are defined as in equation (11)-(14) with $\Delta a, \Delta b, \Delta c$ as the time-varying value of the system parameters and $\delta(t)$ is lumped uncertainty.

$$
\begin{gathered}
e(\mathrm{t})=\omega_{r}^{\prime \prime}(\mathrm{t})-\omega_{r}(\mathrm{t}) \\
\dot{\epsilon}(\mathrm{t})=-a \epsilon(\mathrm{t})-b i_{q}^{\prime \prime}(\mathrm{t})+\emptyset(\mathrm{t})+\delta(\mathrm{t}) \\
a=B_{w} / J, b=k / J, c=T J J \\
\emptyset(\mathrm{t})=a \omega_{r}^{*}(\mathrm{t})+c(\mathrm{t})+\dot{\omega}_{\mathrm{r}}^{*}(\mathrm{t}) \\
\delta(\mathrm{t})=\Delta a \omega_{\mathrm{r}}(\mathrm{t})-\Delta b i_{q}^{*}(\mathrm{t})+\Delta c(\mathrm{t}) \\
|\delta(\mathrm{t})| \leq \Omega, \Omega \in R^{+}
\end{gathered}
$$

\section{FOSMC-PID CONTROLLER DESIGN}

\section{A. Design of FOSMC-PID}

In this study, a fractional PID $\left(\mathrm{PI}^{\alpha} \mathrm{D}^{\beta}\right)$ sliding surface is proposed and the sliding surface is defined as in equation (15), where ${ }_{0} D_{t}^{-\alpha}($.$) is a fractional integration of order \alpha$ and ${ }_{0} D_{t}^{\beta}($.$) is a fractional differentiation of order \beta$. By selecting $\alpha=\beta=1$, a classical integer order PID sliding surface is obtained. Control law in equation (16) is adopted in this study. The equivalent control law in equation (17) is obtained.

$$
\begin{gathered}
s(t)=k_{p} e(t)+k_{i} a D_{t}^{\alpha} e(t)+k_{d} D_{t}^{\beta} e(t) \\
k_{p} k_{p} k_{d}>0,0<a<1, \quad 0<\beta<1 \\
s=-w s-k_{s} \operatorname{sign}(s), \quad w, k_{s} \in R^{+} \\
i_{q}(t)=\left(b k_{p}\right)^{-l}\left[\begin{array}{c}
k_{i} D_{t}^{J-a} e(t)+{ }_{0} D_{t}^{\beta+1} e(t) \\
+(w-a) k_{p} e(t) \\
+k_{p} \emptyset(t)+w k_{i} D_{i}^{-a} e(t) \\
+w_{0} D_{i}^{\beta} e(t)+k_{s} \operatorname{sign}(s)
\end{array}\right]
\end{gathered}
$$

\section{B. Stability analysis}

Reaching condition of the proposed fractional sliding manifold has to be satisfied to ensure convergence of system state to the manifold for any initial condition. For this purpose, Lyapunov stability theorem is used, where the Lyapunov function candidate is chosen to be $V=(1 / 2) s^{2}$ for system initial states $t_{0} \neq 0$. The reaching condition is satisfied when $V<0$ holds or $s s<0$. From equation (18), it shows that $V<0$ holds when $k_{s}>k_{p}|\delta(t)|$ is satisfied or $\left(k_{s} / k_{p}\right)>/ \delta(1) /$ is satisfied. Assumed that $|\delta(t)| \leq \emptyset \in R^{+}$, then, according to Lyapunov stability theorem, the reaching condition of the proposed FOSMC is satisfied if $\left(k_{0} / k_{p}\right)>\emptyset$. In addition, Zhang, et al. [4] has proven that with the chosen control law, system will converge to the switching manifold at any initial state when inequality (19) is satisfied.

$$
\begin{gathered}
V=-w s^{2}-k_{s}|s|+k_{p} \delta(t) s \\
t \geq \mathrm{t}_{0}-(1 / w) \ln \left(k_{s} / w\left|s\left(\mathrm{t}_{0}\right)\right|+k_{s}\right)
\end{gathered}
$$

After reaching condition is ensured, the stability of the system during sliding phase has to be analysed. For that purpose, Lemma below is presented, followed by its corresponding theorem and proof.

Lemma. [28] The following autonomous fractional order system is considered,

$$
{ }_{0} D_{1}^{\prime} x(t)=A x(t), \quad x(0)=x_{0}
$$

where $x \in R^{n}, \quad A=\left(a_{i}\right) \in R^{m x n}, \quad 0<r<1$, is asymptotically stable if and only if

$$
|\arg (\operatorname{eig}(A))|>r(\pi / 2)
$$

Theorem. System in equation (15) is stable when conditions $k_{p}, k_{1}, k_{d}>0$ and $0<\alpha, \beta<1$ are synchronously satisfied.

Proof. When sliding mode occurs, the sliding mode dynamics is represented in matrix form as in equation (22).

$$
\left[\begin{array}{l}
{ }_{0}^{\alpha}\left(e_{1}\right) \\
{ }_{\alpha}^{\beta}\left(e_{1}\right)
\end{array}\right]=\left[\begin{array}{cc}
0 & 1 \\
-\left(k_{i} / k_{d}\right) & -\left(k_{p} / k_{d}\right)
\end{array}\right]\left[\begin{array}{l}
e_{1} \\
e_{2}
\end{array}\right]=A\left[\begin{array}{l}
e_{1} \\
e_{2}
\end{array}\right]
$$


By Lemma, system (15) is stable if the condition in (21) is satisfied. Since $0<\alpha, \beta<1$ is satisfied, hence, $0<\alpha(\pi / 2)<(\pi / 2)$ and $0<\beta((\pi / 2)<(\pi / 2)$. Stability condition in Lemma is satisfied if $k_{p}, k_{i}$ and $k_{d}$ are selected to be positive.

\section{SIMULLATION RESULTS}

The proposed FOSMC in Fig. 1 is simulated in MATLAB/Simulink environment to evaluate its performance as a speed regulator. $\alpha$ and $\beta$ was chosen to be 0.35 and 0.3 respectively. Reference speed of $500 \mathrm{rpm}$ was set and load torque of $2 \mathrm{Nm}$ was applied at $\mathrm{t}=0.5 \mathrm{~s}$.

\section{A. Performance comparison of Fractional Order SMC with conventional integer order SMC}

The performance of the proposed fractional order SMC is compared with the conventional SMC. Result in Fig. 2 show that drive system with SMC speed controller experienced $9.22 \%$ overshoot, which was 10 times higher than overshoot of the FOSMC system. The recorded settling time for SMC system was more than 30 times longer than FOSMC system. When load torque was applied, SMC system suffered from speed drop of almost the same as those of FOSMC system. However, it took almost 25 times longer time to settle back to the reference speed compared to the FOSMC system. Furthermore, in system with conventional SMC, 10 times higher speed ripple was observed.

\section{B. Performance comparison of Fractional Order SMC with different sliding surface designs ( $P I, P D$ and $P I D)$}

In this work, a fractional PID sliding surface was proposed to construct the sliding mode controller. From Fig. 3, it can be seen that FOSMC with PID sliding surface resulted in better speed response with almost 19 times less overshoot than FOSMC with PI sliding surface. When load torque of $2 \mathrm{Nm}$ was applied, FOSMC-PI experienced a speed drop of $4 \%$, which is $2.8 \%$ more than the speed drop of a FOSMC-PID system. After the speed drop, the FOSMC-PI system settled back to reference speed after almost $0.01 \mathrm{~s}$, whereas the FOSMC-PID settled faster by one fifth. In terms of torque ripple, the performance of FOSMC-PID was prominent, where the resulting torque ripple was half of the torque ripple of FOSMC-PI. Fig. 4 shows that FOSMC-PD resulted in no overshoot compared to FOSMC-PID. However, its settling time was almost 9 times longer than FOSMC-PID. In addition to that, FOSMC-PD had a larger steady state error of almost 3 times higher than FOSMC-PID. Torque ripple of both controllers was almost equal.

In its own fractional order SMC group, the proposed FOSMC-PID has shown its advantages in balancing the individual strength and weaknesses of FOSMC-PI and FOSMC-PD. The proposed FOSMC reduced the overshoot contributed by the integral portion and at the same time reduce the steady state error contributed by the differential portion. The combination of PID also reduces the speed drop when the load torque was applied. Small speed and torque ripple proves that chattering phenomenon has been successfully suppressed. Performance indices of the proposed controller and the controllers in comparison are summarized in TABLE I.

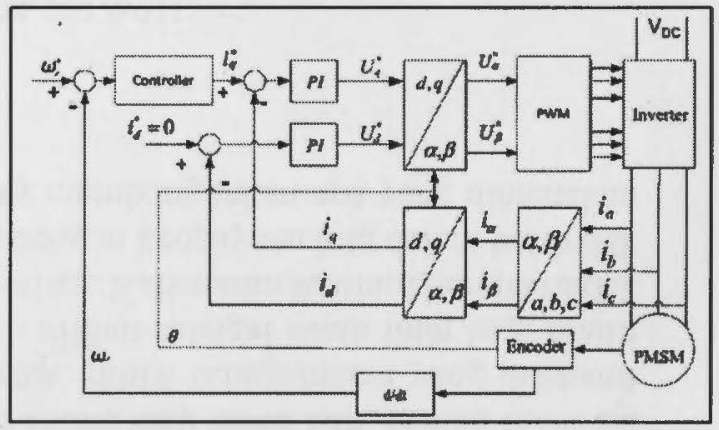

Fig. 1. Block diagram of the proposed control scheme

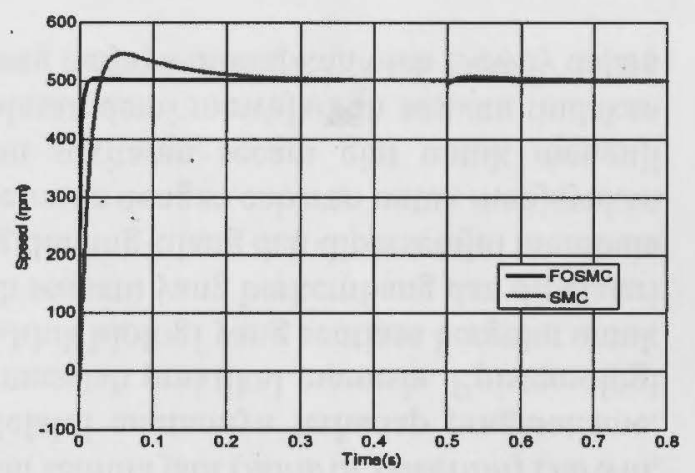

Fig. 2. Speed response of the proposed FOSMC and conventional SMC speed controller

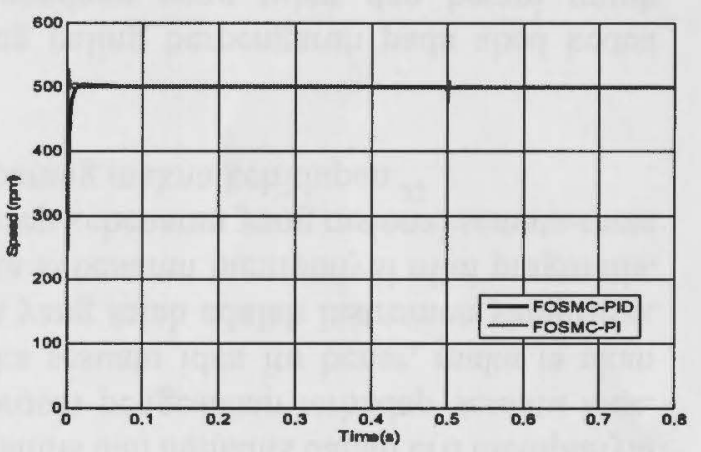

Fig. 3. Speed response of FOSMC-PID and FOSMC-PI speed controller

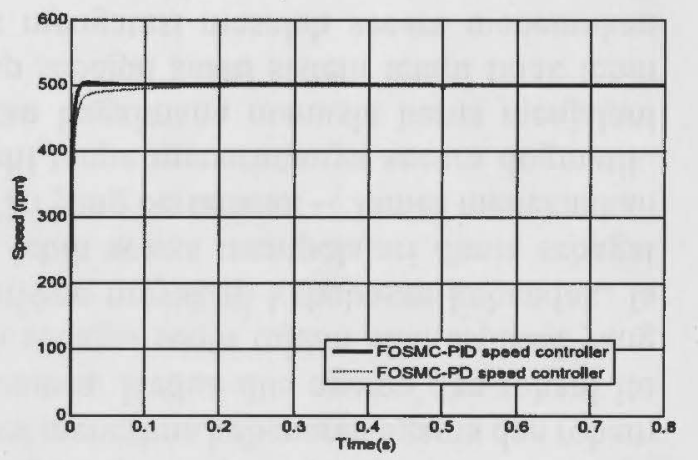

Fig. 4. Speed response of FOSMC-PID and FOSMC-PD speed controller 
TABLE 1. COMPARISON OF PERFORMANCE INDICES OF THE PROPOSED CONTROLLER WITH PREVIOUS WORKS

\begin{tabular}{|c|c|c|c|c|}
\hline $\begin{array}{c}\text { Performance } \\
\text { indices }\end{array}$ & $\begin{array}{c}\text { SMC } \\
{[29]}\end{array}$ & $\begin{array}{c}\text { FOSMC } \\
\text {-PI [4] }\end{array}$ & $\begin{array}{c}\text { FOSMC- } \\
\text { PD [25] }\end{array}$ & $\begin{array}{c}\text { FOSMC- } \\
\text { PID } \\
\text { (proposed) }\end{array}$ \\
\hline Overshoot (\%) & 9.22 & 5.52 & 0 & 0.8593 \\
\hline Settling time (s) & 0.288 & 0.0094 & 0.096 & 0.0096 \\
\hline Speed drop (\%) & 1.28 & 4.3 & 1.5 & 1.16 \\
\hline $\begin{array}{c}\text { Steady state error } \\
\text { (\%) }\end{array}$ & 0.02 & 0.04 & 0.06 & 0.02 \\
\hline Torque ripple (\%) & 12 & 11 & 10 & 10 \\
\hline Speed ripple (\%) & 0.16 & 0.12 & 0.014 & 0.014 \\
\hline
\end{tabular}

\section{CONCLUSION}

A fractional order sliding mode speed control of PMSM has been proposed in this research. With the proposed controller, the motor reached the command speed faster from standstill with a little overshoot. After a small speed drop, the motor speed settled back to the command speed faster and with negligible steady state error when load torque is applied. The proposed FOSMC speed controller performs as a robust and fast anti-disturbance controller to regulate the speed of a PMSM and proven its advantages against conventional SMC controller. The proposed sliding surface design also improves the FOSMC in terms of torque ripple reduction, chattering reduction and anti-disturbance properties, compared to FOSMC with PI or PD sliding surface.

\section{REFERENCES}

[1] L. Shihua, Z Mingming and $Y$. Xinghuo, "Design and implementation of terminal sliding mode control method for PMSM speed regulation system," IEEE Transactions on Industrial Informatics, vol. 9, pp. 1879-1891, 2013.

[2] P. Pillay and R. Krishnan, "Modeling, simulation, and analysis of permanent-magnet motor drives. I. The permanent-magnet synchronous motor drive," IEEE Transactions on Industry Applications, vol. 25, pp. 265-273, 1989.

[3] W. Gou-Jen, F. Chuan-Tzueng, and K. J. Chang, "Neural-networkbased self-tuning PI controller for precise motion control of PMAC motors," IEEE Transactions on Industrial Electronics, vol, 48, pp. $408-415,2001$.

[4] B. Zhang, Y. Pi, and Y. Luo, "Fractional order sliding-mode control based on parameters auto-tuning for velocity control of permanent magnet synchronous motor, "ISA Transactions, vol. 51, pp. 649-656, 2012.

[5] Shihua Li, Kai Zong, and Huixian Liu, "A composite speed controller based on a second-order model of permanent magnet synchronous motor system," Transactions of the Instirute of Measurement and Control, vol. 33, pp. 522-541, 2011.

[6] Z. Xiaoguang, S. Lizhi, Z. Ke, and S. Li, "Nonlinear speed control for PMSM system using sliding mode control and disturbance compensation techniques," IEEE Transactions on Power Electronics, vol. 28, pp. 1358-1365, 2013.

[7] F. F. M. El-Sousy, "Robust wavelet-neural-network sliding-mode control system for permanent magnet synchronous motor drive," IET Electric Power Applications, vol. 5, pp. 113-132, 2011.

[8] L. Huixian and L. Shihua, "Speed control for PMSM servo system using predictive functional control and extended state observer," IEEE Transactions on Industrial Electronics, vol. 59, pp. 1171-1183, 2012.

[9] R. Errouissi, M. Ouhrouche, C. Wen-Hua, and A. M. Trzynadlowski, "Robust nonlinear predictive controller for permanent magnet synchronous motors with an optimized cost function," IEEE Transactions on Industrial Electronics, vol. 59, pp. 2849-2858, 2012.
[10] J. Zhou and Y. Wang, "Adaptive backstepping speed controller design for a permanent magnet synchronous motor," IEE Proceedings - Electric Power Applications, vol. 149, pp. 165-172, 2002.

[11] N. T.-T. Vu, H. H. Choi, and J.-W. Jung, "Certainty equivalence adaptive speed controller for permanent magnet synchronous motor," Mechatronics, vol. 22, pp. 811-818, 2012

[12] C. Han Ho, V. Nga Thi-Thuy, and J. Jin-Woo, "Digital implementation of an adaptive speed regulator for a PMSM," IEEE Transactions on Power Electronics, vol. 26, pp. 3-8, 2011.

[13] Y. X. Su, C. H. Zheng, and B. Y. Duan, "Automatic disturbances rejection controller for precise motion control of permanent-magnet synchronous motors," IEEE Transactions on Industrial Electronics, vol. 52, pp. 814-823, 2005.

[14] C. Han Ho and J. Jin-Woo, "Discrete-time fuzzy speed regulator design for PM synchronous motor, "IEEE Transactions on Industrial Electronics, vol. 60, pp. 600-607, 2013.

[15] V. Utkin, "Variable structure systems with sliding modes," IEEE Transactions on Automatic Control, vol. 22, pp. 212-222, 1977.

[16] J. Y. Hung, W. Gao, and J. C. Hung, "Variable structure control: a survey," IEEE Transactions on Industrial Electronics, vol, 40, pp. 222, 1993.

[17] C. Syuan-Yi. and L. Faa-Jeng, "Robust nonsingular terminal sliding mode control for nonlinear magnetic bearing system," IEEE Transactions on Control Systems Technology, vol. 19, pp. 636-643 2011.

[18] Z. Bao-Lin, H. Qing-Long, Z. Xian-Ming, and Y. Xinghuo, "Sliding mode control with mixed current and delayed states for offshore steel jacket platforms," IEEE Transactions on Control Systems Technology, vol, 22, pp. 1769-1783, 2014.

[19] L. Jeng-Dao, K. Suiyang, and W. Zhi-Bin, "DSP-based sliding mode control for electromagnetic levitation precise position system," IEEE Transactions on Industrial Informatics, vol. 9, pp. 817-827, 2013.

[20] B. A. Elsayed, M. A. Hassan, and S. Mekhilef, "Fuzzy swinging-up with sliding mode control for third order cart-inverted pendulum system," International Joumal of Control, Automation and Systems, vol. 13, pp. 238-248, February 012015.

[21] A. Aimad, K. Madjid, and S. Mekhilef, "Robust sensorless sliding mode flux observer for DTC-SVM-based drive with inverter nonlinearity compensation," Joumal of Power Electronics, vol."14, pp. 125-134, 2014

[22] C. J. Fallaha, M. Saad, H. Y. Kanaan, and K. Al-Haddad, "Sliding mode robot control with exponential reaching law," IEEE Transactions on Industrial Electronics, vol. 58, pp. 600-610, 2011.

[23] K. D. Young, V. I. Utkin, and U. Ozguner, "A control engineer's guide to sliding mode control," IEEE Transactions on Control Systems Technology, vol. 7, pp. 328-342, 1999.

[24] V. I. Utkin, "Sliding mode control design principles and applications to electric drives," IEEE Transactions on Industrial Electronics, vol. 40, pp. 23-36, 1993.

[25] J. Huang, H. Li, F. Teng, and D. Liu, "Fractional order sliding mode controller for the speed control of a permanent magnet synchronous motor," in 24th Chinese Control and Decision Conference (CCDC), 2012, pp. 1203-1208.

[26] E. M. Jafarov, M. N. A. Parlakci, and Y. Istefanopulos, "A new variable structure PID-controller design for robot manipulators," IEEE Transactions on Control Systems Technology, vol. 13, pp. 122130,2005 .

[27] M. Li, F. Wang, and F. Gao, "PID-based sliding mode controller for nonlinear processes," Industrial and Engineering Chemistry Research, vol, 40, pp. 2660-2667, 2001.

[28] D. Matignon, "Stability results for fractional differential equations with applications to control processing, ${ }^{\text {" IEEE-SMC Computational }}$ Engineering in Systems Applications, vol. 2, pp. 963-968, 1996.

[29] M. Zaky, "Adaptive and robust speed control of interior permanent magnet synchronous motor drives," Electrical Engineering, vol. 94, pp. 49-58, 2012. 